\title{
THE MEASUREMENT OF CURIOSITY OF TEACHER CANDIDATES: A STUDY BASED ON BREADTH AND DEPTH OF INTEREST
}

\author{
Neslisah Aktas \\ Gazi University Institute of Education Sciences, Ankara, Turkey \\ aktas.neslisah@gmail.com \\ Umit Dogan Ustun \\ Dumlupinar University School of Physical education and Sports, Kutahya, Turkey \\ umit.dogan.ustun@gmail.com
}

\begin{abstract}
The aim of this study was to investigate curiosity styles of teacher candidates. A total of 250 teacher candidates -classroom/physical education and sports- volunteered for the study. In the study Turkish version of Erwin's (1998) two-factor curiosity scale was used as data gathering tool. In the evaluation of data first reliability and normality analyses were made. And MANOVA was used as hypothesis test at the \%95 confidence level. This study showed that classroom teacher candidates' breadth of interest curiosity score was significantly higher in comparison with physical education and sport teacher candidates.
\end{abstract}

Keywords: Curiosity, Breadth, and Depth of interest; Education; Teacher Candidates.

\section{Introduction}

Human has always been a social being, and for to function efficiently in a changing and complex social environment, has required information about those around (Foster, 2004). But how can we explain this kind of search? In some occasions the answer of the question is curiosity. Consequently, humankind's natural curiosity has been a major motive behind the scientific discovery and the advancement of civilisation (Cavojova \& Sollar 2007).

Curiosity reflects a state in which people lack information and are motivated to find out what it is (Noordewier \& van Dijk 2015). Although many researchers tried to clarify curiosity, most of the pioneering approaches done by Berlyne in the 1950s. In his studies, Berlyne explained curiosity through theories such as drive reduction. According to this theory, curiosity is an appetite, such as hunger that needs satiation (Berlyne, 1954; 1960). But researchers have conceptualised curiosity as the desire for new information and knowledge (Loewenstein, 1994) and tried to understand and identify curiosity in multidimensional ways. For example, while Colins, Litman, and Spielberger (2004) studied perceptual curiosity, Litman and Spielberger (2003) studied epistemic curiosity, and each facet of curiosity differs from each other. For example, while perceptual curiosity refers to the acquisition of new information by sensory stimulation, epistemic curiosity refers to the tendency to seek out opportunities for acquiring facts, knowledge, and ideas (Colins, Litman \& Spielberger, 2004; Litman \& Spielberger, 2003).

Another dimension of the curiosity arouses from the question: is curiosity a trait or a state part of characteristic? According to Berlyne (1954), curiosity arose only within specific situations and therefore cannot be a trait. But Kashdan and colleagues (2004) disagree with this view and add; curiosity arouses when it is intrinsically reinforced and therefore it has a continuum form. Besides, Dewey (1910) explained three forms of curiosity as a) physical, b) social, c) intellectual curiosity. According to Dewey physical curiosity can be found intrinsically in every human and has no or very small goal, but social curiosity has an intellectual side but not as much as the intellectual curiosity because it is simply an attempt to get more knowledge. According to the third type of curiosity which Dewey explained, intellectual curiosity arouses when we think there is something more hidden or behind that meets the eye (Reiro et al., 2006). Although Dewey distinguished curiosity from interest researchers considered interest as a sub-dimension of curiosity (Langevin, 1971; Ainley, 1987; Giampra, Camp \& Grodsky, 1992).

\section{Breadth- and depth-of-interest curiosity}

When we look at the definitions on breadth and depth of interest curiosity we can see that while depth curiosity refers to curiosity for ideas and experiences directed in a more sustained manner toward a single topic, breadth curiosity refers to curiosity about many different topics, ideas or experiences in a constant search for variation (Loewenstein, 1994; Grossnickle, 2016).

Approaches to breadth and depth of interest curiosity pioneered by Langevin. He introduced the breadth- and depth-of-interest curiosity distinction through his exploratory factor-analytic research using five 
curiosity measures and a sample of 269 children who were 12 years old. Although latterly in 1976 Langevin reconsidered his previous study and rejected the distinction between breadth and depth factors of curiosity, Ainley (1987) extended Langevin's research and fixed the difficulties associated with Langevin's 1976 study by using a much larger sample $(\mathrm{N}=227)$ and by using exploratory factor-analytic procedures. Ainley also used self-report measures and college students (Mage $=20$ years). She found tenable two- and three-factor solutions, but selected a two-factor solution most closely aligned with Langevin's breadth- and depth-ofinterest scales. Ainley concluded that Langevin's (1971) early work was tentatively supportable and that curiosity consisted of two parsimonious factors: breadth- and depth-of-interest (Reiro et al., 2006).

\section{Breadth- and depth-of-interest curiosity in Educational Context}

Curiosity appears in educational contexts in several ways. It supports both the process and the outcomes of learning (Spielberger \& Starr, 1994) and consequently, these dimensions of curiosity have received some recent attention in educational contexts (e.g., Deringöl et al., 2010; Bahadır \& Certel, 2013). In their study Bahadır and Certel examined breadth, depth and overall curiosity of physical education and other branch teachers mutually $(\mathrm{N}=388)$ according to socio-demographic features and specified higher overall curiosity for female teachers and lower overall curiosity for physical education and sports teachers (Bahadir \& Certel, 2013). In a similar study conducted by Deringöl and colleagues, study findings revealed higher breadth curiosity than depth curiosity in teacher candidates $(\mathrm{N}=155)$ and higher overall curiosity for females (Deringol et al., 2010). Demirel and Coskun (2009) also indicated high breadth curiosity for university students. Although previous studies showed some empirical findings, personal factors have always been determinants for curiosity in an education process. Besides curriculums taught for physical education and sport faculty students vs. faculty of education students differ in many ways. Given this overviewed information, this paper examined breadth- and depth-of-interest curiosity for physical education and classroom teacher candidates.

\section{Material and Method}

\section{Research Sample}

Research sample constituted of 120 physical education and sport teacher candidates and 130 classroom teacher candidates of Dumlupinar University (Mage22.23 \pm 1.56 ).

\section{Data Gathering Tool}

In the study, we used the Breadth- and depth-of-interest curiosity by Erwin (1998), which comprises of two dimensions: Breadth and Depth of curiosity. The Turkish adaptation of the scale was done by Demirel and Coskun (2009) using exploratory factor-analytic research. The Turkish version of the scale consists of 47 items and two dimensions (breadth 27 items and depth 20 items) and anchored with 6 Likert-type scales. Cronbach's Alpha for the scale calculated by Demirel and Coskun as .93.

\section{Procedure}

The data obtained in the spring semester of the 2013-2014 academic year by the researchers using face to face method in order to control the consistency of the answers given for the scale.

\section{Analysis of the data}

In the evaluation of the data first Cronbach's Alpha calculated for the scale as a means of reliability for the whole scale and dimensions. And Cronbach's Alpha calculated for the whole scale as .90 ( $\mathrm{N}$ of items $=47)$, for Breadth dimension as $.857(\mathrm{~N}$ of items=27), and for Depth dimension as $.769(\mathrm{~N}$ of items= 20). Than skewness and kurtosis values examined and finally in order to avoid type 1 error MANOVA conducted as hypothesis test $(\alpha=.05)$.

\section{Results}

Table 1 includes demographic information of the participants. According to analyse results $\% 80.4$ $(\mathrm{N}=201)$ of the participants are below the age of 24, \%56.4 $(\mathrm{N}=141)$ are male, \%52.0 $(\mathrm{N}=130)$ are studying at the faculty of education, \%40.8 $(\mathrm{N}=102)$ are 3 class students and $\% 72.8(\mathrm{~N}=182)$ have lower GPA than 3.00 . 
Demographic information of the participants

\begin{tabular}{|c|c|c|c|}
\hline & & $\mathbf{F}$ & $\%$ \\
\hline & $\geq 24$ & 49 & 19.6 \\
\hline \multirow[t]{2}{*}{ Age } & $<24$ & 201 & 80.4 \\
\hline & Total & 250 & 100.0 \\
\hline \multirow{3}{*}{ Gender } & Male & 141 & 56.4 \\
\hline & Female & 109 & 43.6 \\
\hline & Total & 250 & 100.0 \\
\hline \multirow{3}{*}{$\begin{array}{l}\text { Department of } \\
\text { Education }\end{array}$} & Physical Education and Sports & 120 & 48.0 \\
\hline & Classroom & 130 & 52.0 \\
\hline & Total & 250 & 100.0 \\
\hline \multirow{5}{*}{ Classroom } & 1 & 24 & 9.6 \\
\hline & 2 & 86 & 34.4 \\
\hline & 3 & 102 & 40.8 \\
\hline & 4 and upper & 38 & 15.2 \\
\hline & Total & 250 & 100.0 \\
\hline \multirow{3}{*}{ GPA } & $\geq 3$ & 68 & 27.2 \\
\hline & $<3$ & 182 & 72.8 \\
\hline & Total & 250 & 100.0 \\
\hline
\end{tabular}

Table 1

MANOVA results according to department of education

\begin{tabular}{clccc}
\hline & & $\mathrm{N}$ & Mean & Std. Deviation \\
\hline \multirow{3}{*}{ Breadth } & Physical education and sports & 120 & 63.44 & 16.19 \\
& Classroom & 130 & 68.00 & 15.29 \\
& Total & 250 & 65.81 & 15.86 \\
& Physical education and sports & 120 & 46.61 & 10.79 \\
& Classroom & 130 & 48.53 & 10.63 \\
& Total & 250 & 47.61 & 10.73 \\
\hline
\end{tabular}

There was no significant difference between physical education and sports and classroom teacher candidates when considered jointly on the variables breadth and depth curiosity, Wilk's $\lambda=.978, \mathrm{~F}_{(2,247)}=$ $2.759, p=.065$, partial $\eta^{2}=.022$. A separate ANOVA was conducted for each dependent variable, with each ANOVA evaluated at an alpha level of .025 . There was a significant difference between physical education and sports and classroom teacher candidates on breadth curiosity, $\mathrm{F}_{(1,248)}=5.239, \mathrm{p}=.023$, partial $\eta^{2}=.021$, with classroom teacher candidates $(\mathrm{M}=68$. $)$ scoring higher than physical education and sports teacher candidates $(M=63.44)$. But there was not a significant difference between physical education and sports and classroom teacher candidates on depth curiosity, $\mathrm{F}_{(1,248)}=2.009, \mathrm{p}=.158$, partial $\eta^{2}=.008$.

\section{Discussion}

Our present study aimed to analyse breadth and depth curiosity of physical education and sports and classroom teacher candidates mutually. According to analyse results classroom teacher candidates scored significantly higher than physical education and sport teacher candidates in breadth dimension. But because of low partial $\eta^{2}(.021)$ ' we doubted that the effect of this significant difference is not too strong and we calculated observed power and calculated as .626 and so we accepted our hypothesis (Brown, 2008). As a result, it can be said that classroom teacher candidates are more curious about many different topics, ideas or experiences in a constant search for variation than physical education and sports teacher candidates (Loewenstein, 1994). In another word, they search for and/or superficially engage with a wide variety of information and they also have a desire to experience a variety of stimuli (Pyle, 2013).

In the literature, there are studies which show similarity to our study's findings. For example, in their study, Bahadir and Certel (2013) revealed lower breadth curiosity for physical education and sports teachers than other branch teachers and indicated this situation as an unexpected result because of the interdisciplinary and multidisciplinary nature of physical education and sports lessons. In a study conducted by Demirel and Coskun (2009) significant differences emerged in breadth curiosity of university students according to their department of education. Our findings show similarity with Demirel and Coskun's findings. 
It is obvious that curiosity appears in the education environment in several ways. So it is important to keep the curiosity alive in order to achieve efficient education and consequences because curiosity is one of the key factors for education.

\section{Limitations and Future Studies}

Although this study revealed significantly higher breadth curiosity for classroom teacher candidates than physical education and sports teacher candidates has some limitations. First, all the participants were from the same university and limited with just two departments and this lead a limited sampling group. Second other personal factors such as gender or age excluded. So, in order to minimise these limitations, future studies may focus on larger sampling groups with more independent variables. Also, it is important to prove the connection between curiosity and education with empirical studies.

\section{Acknowledgements}

An earlier version of this study was presented at International Conference on Education, Law and Disaster Management (ELDM-16) May, 24-25 Paris (France).

\section{References:}

Ainley, M.D. (1987). The factor structure of curiosity measures: breadth and depth of interest curiosity styles. Australian Journal of Psychology, 39, 53-59. https://doi.org/10.1080/00049538708259035

Bahadır, Z., \& Certel, Z. (2013). Comparison of curiosity levels of physical education teachers to the teachers of other branches. Turkish Journal of Sport and Exercise, 15 (1), 1-8.

Berlyne, D. E. (1954). A theory of human curiosity. British Journal of Psychology, 45 (3), 180-191. https://doi.org/10.1111/j.2044$\underline{\text { 8295.1954.tb01243.x }}$

Berlyne, D. E. (1960). Conflict, arousal and curiosity. New York: McGraw-Hill. https://doi.org/10.1037/11164-000

Brown, J. D. (2008). Effect size and eta squared. Shiken: JALT Testing \& Evaluation SIG Newsletter, 12 (2), 38-43.

Collins, R. P., Litman, J. A., \& Spielberger, C. D. (2004). The measurement of perceptual curiosity. Personality and Individual Differences, 36, 1127-1141. https://doi.org/10.1016/s0191-8869(03)00205-8

Covojova, V. \& Sollar, T. (2007). The curiosity and exploration inventory: structure and reliability. Studia Psychologica, 49, 89-100.

Demirel, M., \& Coşkun, Y. D. (2009). Evaluation of curiosity levels of university students in terms of some variables. Mehmet Akif Ersoy University Education Faculty Journal, 18, 111-134.

Deringöl, Y., Yaman, Y., Özsarı, İ., \& Gülten, D. Ç. (2010). Evaluation of curiosity levels of candidate primary school teachers. International Conference on New Trends in Education and Their Implementations, 11-13 November, Antalya, Turkey.

Foster, E. K. (2004). Research on gossip: taxonomy, methods, and future directions. Review of General Psychology, 8, 78-99. https://doi.org/10.1037/1089-2680.8.2.78

Giambra, L. M., Camp, C. J., \& Grodsky, A. (1992). Curiosity and stimulation seeking across the adult life span: cross-sectional and 6 to 8-year longitudinal findings. Psychology and Aging, 7, 150-157. https://doi.org/10.1037//0882-7974.7.1.150

Grossnickle, E. M. (2016). Disentangling curiosity: dimensionality, definitions, and distinctions from interest in educational contexts. Educ Psychol Rev, 28, 23-60. https://doi.org/10.1007/s10648-014-9294-y

Kashdan, T. B., Rose, P., \& Fincham, F. D. (2004). Curiosity and exploration: facilitating positive subjective experiences and personal growth opportunities. Journal of Personality Assessment, 82, 291-305. https://doi.org/10.1207/s15327752jpa8203_05

Langevin, R. (1971). Is curiosity a unitary construct? Canadian Journal of Psychology, 25, 360-374. https://doi.org/10.1037/h0082397

Litman, J. A., \& Spielberger, C. D. (2003). Measuring epistemic curiosity and its diversive and specific components. Journal of Personality Assessment, 80, 75- 86. https://doi.org/10.1207/s15327752jpa8001 16

Loewenstein, G. (1994). The psychology of curiosity: a review and reinterpretation. Psychological Bulletin, 116, 75-98. https://doi.org/10.1037//0033-2909.116.1.75

Noordewier, M. K., \& van Dijk, E. (2015). Curiosity and time: from not knowing to almost knowing. Cognition and Emotion, https://doi.org/10.1080/02699931.2015.1122577

Pyle, L.K. (2013). Changes in leadership self-efficacy, leader identity, capacity for socially responsible leadership, and curiosity due to a structured leader development program. Dissertations Paper 93. Retrieved online from: http://commons.lib.jmu.edu/diss201019

Reiro, T. G., Petrosko, J. M., Wiswell, A. K., \& Thongsukmag J. (2006). The measurement and conceptualization of curiosity. The Journal of Genetic Psychology, 167 (2), 117-135. https://doi.org/10.3200/gntp.167.2.117-135

Spielberger, C. D., \& Starr, L. M. (1994). Curiosity and exploratory behavior. In H. F. O’Neil Jr. and M.Drillings (Eds), Motivation Theory and Research, (pp. 241-243). Hillsdale: Lawrence Erlbaum. 